\title{
Pengaruh Kultur Serta Kebiasaan dan Pembiasaan Positif Di Sekolah Terhadap Karakter Religius dan Peduli Lingkungan Siswa SD Di Kota Cirebon
}

\author{
Tarmidzi, lis Yeni Sugiarti \\ Universias Swadaya Gunung Jati \\ mulyatarmidzi@gmail.com
}

\author{
Sejarah Artikel \\ diterima 26/10/2019
}

disetujui 04/11/2019

diterbitkan 14/12/2019

\begin{abstract}
Some characters influencing child development such as heredity, and developmental environment (Yusuf, 2006:31). The student developmental environment covers family, school, peer, and social environment. Setiati (2014) said that school culture or work climate describes the atmosphere and relation inter teacher, between teacher and principal, teacher and staff, and department around. We can also say that the culture moral is very important to create an effective atmosphere between principals, teachers, and students to set an example values grade in school. The researcher chooses a couple of samples based on a purposive sampling technique. After data collection, the researcher does the test to look for an influence of positive habituations and school culture toward the religious and caring of environment characters of the primary student. It was concluded that positive habituations and school culture are influencing the religious and caring of environment characters of the primary student in Cirebon City.
\end{abstract}

Keywords: positive habituations, school culture, religious character, caring of environment character

\begin{abstract}
Abstrak
Ada beberapa faktor yang memengaruhi perkembangan anak, diantaranya adalah faktor keturunan (hereditas) dan lingkungan perkembangan. Lingkungan perkembangan siswa meliputi lingkungan keluarga, sekolah, teman sebaya, dan masyarakat. Setiyati (2014) mengemukakan bahwa budaya sekolah memberi gambaran hubungan antara guru dengan guru, guru dengan pimpinan sekolah, guru dengan staf sekolah, dan dinas di lingkungannya. Dapat dikatakan bahwa budaya moral di sekolah sangat diperlukan agar terciptanya suasana yang efektif antara kepala sekolah, guru, serta siswa untuk meneladani nilai-nilai yang ada di sekolah. Peneliti memilih sampel beberapa sekolah dasar di kota Cirebon menurut teknik purposive sampling. Pada data kemudian dilakukan uji untuk melihat besar pengaruh variabel bebas (kultur dan pembiasaan positif) terhadap variabel terikatnya (karakter religius dan peduli lingkungan). Simpulan yang diambil adalah pernyataan bahwa Karakter religius dan kepedulian siswa terhadap lingkungan cukup dipengaruhi oleh kultur serta pembiasaan positif di sekolah.

Kata kunci: kultur sekolah, kebiasaan dan pembiasaan positif, karakter religius, karakter peduli lingkungan
\end{abstract}




\section{PENDAHULUAN}

Pendidikan pada masa anakanak akan menjadi pondasi bagi perkembangan pemikiran dan karakternya di masa depan nanti. Pendidikan bermakna pada masa sekolah akan tersimpan dalam memori jangka panjangnya. Pendidikan sendiri menurut teori behaviorisme adalah upaya untuk merubah perilaku. Perubahan perilaku yang dimaksudkan dalam pendidikan tentu saja adalah peningkatan perilaku menjadi lebih baik. Perilaku yang baik menunjukkan kedewasaan, tanggung jawab dan berkembangnya seluruh potensi baik dalam diri anak-anak tersebut, seperti kreatif, produktif, dan inovatif yang dilandasi oleh nilai-nilai rohani (religius), jasmani, intelektual, sosial, adat istiadat (kultur/budaya) dan emosional (Willis, 2012).

Ada beberapa faktor yang memengaruhi perkembangan anak, diantaranya adalah faktor keturunan (hereditas) dan lingkungan perkembangan (Yusuf, 2006). Lingkungan adalah setiap hal yang berada di luar individu yang mencakup keadaan fisik dan sosial (Kathena, 1992 dalam Yusuf, 2006). Lingkungan perkembangan siswa meliputi lingkungan keluarga, sekolah, teman sebaya, dan masyarakat. Sekolah merupakan substitusi keluarga, dalam hal ini sekolah memiliki peran sebagai pengganti lingkungan keluarga, sedangkan guru menjadi pengganti orang tua di lingkungan pendidikan yang formal, sehingga sekolah menjadi salah satu faktor penting penentu perkembangan pola pikir, sikap maupun perilaku anak.

Banyaknya kasus kekerasan serta kejahatan yang dilakukan oleh remaja dan dewasa sangat mungkin disebabkan kurang tertanamnya nilainilai religius, sosial, budaya dan emosional dalam diri sejak usia sekolah. Sekolah menjadi salah satu faktor yang menentukan pembentukan karakter dan pola pikir anak. Karakter dan pola pikir anak di sekolah dibentuk melalui kultur (budaya) serta kebiasaan dan pembiasaan positif di sekolah. Kultur sekolah menurut Deal \& Kennedy (Depdiknas, 2003; Jumadi, 2005) meliputi ketentuan dan norma yang disepakati dan menjadi pengikat kuat kebersamaan seluruh warga masyarakat (sekolah). Seluruh norma, nilai, ritual, dan iklim adalah manifestasi dari kultur (Schein dalam MacNeil, 2009).

Setiyati (2014) mengemukakan budaya sekolah memberi gambaran hubungan antara guru dengan guru, guru dengan pimpinan sekolah, guru dengan staf sekolah, dan dinas di lingkungannya. Lickona (2008) Beberapa budaya moral positif di sekolah yang dikemukakan oleh Lickona (2008) dapat diuraikan sebagai berikut.

1. Kepemimpinan akademis dan moral yang dimiliki kepala sekolah

2. Disiplin dalam lingkungan sekolah yang sehingga memberi teladan, dan mendorong serta menjunjung tinggi nilai-nilai yang ada di lingkungan sekolah

3. Kesadaran seluruh masyarakat lingkungan sekolah

4. Kelompok kerja siswa yang membawa seluruh siswa agar mampu mengurus diri sendiri serta menimbulkan perasaan "ini adalah sekolah kami, sehingga kami bertanggung jawab untuk menjadikan sebagai sekolah terbaik" 
5. Suasana moral yang meliputi sikap saling menghormati, keadilan dan kerjasama yang melekat dalam bentuk hubungan antar warga sekolah.

6. Menjunjung tinggi etika dengan memberikan waktu khusus untuk mengganti urusan moral.

\subsection{Karakter}

Karakter adalah

watak/tabiat/kepribadian/sifat-sifat

berdasarkan nilai-nilai yang diyakini dan melekat kuat dalam diri seseorang yang mendasari tindakantindakan yang dilakukan. Watak tersebut bersifat tetap sehingga menjadi pembeda antara seseorang dengan yang lainnya (Mujtahidin, 2017). Hal ini sejalan dengan pendapat Gunawan (2017) bahwa karakter adalah keadaan asli yang ada dalam diri individu seseorang yang membedakan antara dirinya dengan orang lain. Dengan demikian karakter merupakan moral yang harus dibangun untuk menumbuhkan sifat yang baik dalam diri seseorang. Menurut Lickona (2008) karakter terbentuk dari tiga macam bagian yang saling berkaitan, yaitu pengetahuan moral (mantifak), perasaan moral (sosiofak) dan perbuatan moral (artifak).

\subsubsection{Karakter Religius}

Mujtahidin (2017) mengungkapkan karakter religius merupakan bentuk aktualisasi dari sikap dan perilaku seseorang yang mencerminkan kepercayaan dan keyakinan terhadap Tuhan YME yang ditunjukan melalui kepatuhan terhadap ajaran agamanya, tidak ingkar, dan taat menjalankan perintah dan menghindari larangan agama. Karakter religius dalam penelitian ini meliputi: kebiasaan peribadatan di sekolah, kebiasaan berdoa setiap melakukan kegiatan, dan berpakaian atau berbusana sopan.

\subsubsection{Karakter Peduli Lingkungan}

Karakter peduli lingkungan merupakan sikap dan tindakan yang berupaya mencegah kerusakan alam di sekitarnya dan mengembangkan upaya-upaya untuk memperbaiki kerusakan alam yang sudah terjadi. Desfandi (2015) mengemukakan penekanan terhadap lingkungan harus pada: (i) pengetahuan tentang penyebab, (ii) pengetahuan tentang efek, dan (iii) pengetahuan tentang strategi untuk berubah, ketika mengadapi masalah lingkungan. Karakter peduli lingkungan dalam penelitian ini meliputi: program kebersihan lingkungan sekolah, program kebersihan di kelas, kebersihan di kamar kecil, penghijauan dan taman, pemanfaatan lahan kosong, pengelolaan sampah, dan perilaku warga sekolah tentang kebersihan lingkungan.

Rumusan masalah dalam penelitian ini dapat diuraikan sebagai berikut.

1. Bagaimanakah gambaran umum karakter religius siswa sekolah dasar di Kota Cirebon berdasarkan hasil penelitian?

2. Bagaimanakah gambaran umum karakter peduli lingkungan siswa sekolah dasar di Kota Cirebon berdasakan hasil penelitian?

3. Apakah terdapat pengaruh antara Kultur dan pembiasaan positif di sekolah terhadap kepedulian tentang lingkungan serta perilaku religius pada siswa SD di wilayah Cirebon?

Berdasarkan rumusan masalah di atas, tujuan penelitian ini adalah untuk mendapatkan gambaran tentang karakter religius dan peduli lingkungan serta pengaruh kultur dan pembiasaan positif di sekolah 
terhadap perilaku religius dan Cirebon terhadap lingkungannya. kepedulian siswa sekolah dasar Kota

\section{METODE}

Penelitian ini bertujuan untuk melihat pengaruh kultur dan pembiasaan positif di sekolah terhadap perilaku religius dan kepedulian siswa sekolah dasar di Kota Cirebon terhadap lingkungannya. Penelitian ini menggunakan metode survei dengan subjek penelitian sebanyak 200 orang siswa sekolah dasar kelas 5 yang diambil dari sampel delapan sekolah di Kota Cirebon. Data kultur serta kebiasan dan pembiasaan positif di sekolah didapat dari lembar observasi, sedangkan data karakter religius dan peduli lingkungan didapat dari lembar wawancara kepada subjek penelitian. Data yang didapat merupakan data berskala ordinal, sehingga untuk dapat diuji pengaruhnya menggunakan uji regresi diperlukan perubahan data dari skala ordinal menjadi skala interval. Perubahan data tersebut dilakukan menggunakan teknik Method of Succesive Intervals (MSI). Setelah data berubah menjadi skala interval, kemudian dilakukan uji normalitas dan uji regresi untuk melihat besar pengaruh antara variabel bebas dengan variable terikatnya.

\section{PEMBAHASAN}

Nilai kultur serta kebiasaan dan pembiasaan positif untuk tiap sekolah didapat melalui kegiatan observasi/pengamatan menggunakan instrumen lembar observasi. Lembar observasi nilai kultur dan pembiasaan positif di sekolah terdiri atas dua pernyataan mengenai kultur sekolah, yakni budaya ide/gagasan/nilai edukasi, diantaranya slogan keagamaan, slogan lingkungan, serta dua pernyataan mengenai budaya sosial, diantaranya peringatan hari besar keagamaan, dan kegiatan piket dan operasi bersih lingkungan sekolah. Adapun nilai kultur serta kebiasaan dan pembiasaan positif untuk tiap sekolah dapat diperlihatkan oleh Gambar 1.

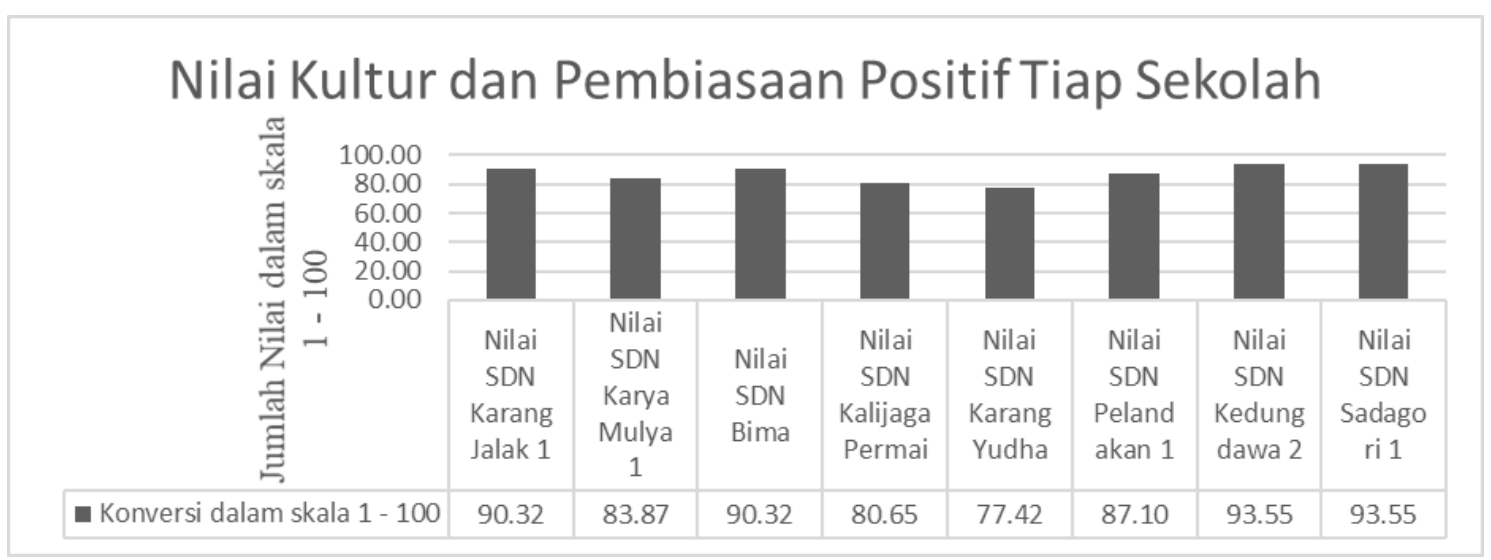

Gambar 1 Nilai Kultur serta Kebiasaan dan Pembiasaan Positif untuk Tiap Sekolah 
Sekolah yang memperoleh nilai $\geq 70$ dikategorikan dalam sekolah yang memiliki nilai "tinggi", sekolah yang memperoleh nilai dalam rentang $40<x$ $<70$ dikategorikan dalam sekolah yang memiliki nilai "sedang", dan sekolah memperoleh nilai $\leq 40$ dikategorikan dalam sekolah yang memiliki nilai "kurang". Berdasarkan kategorisasi tersebut, ternyata untuk seluruh sekolah yang dilaksanakan penelitian memiliki nilai/skor $>70$ yang berarti bahwa nilai kultur serta kebiasaan dan pembiasaan positif untuk tiap sekolah berada dalam kategori tinggi atau dapat dikatakan bahwa tiap sekolah memiliki nilai kultur serta kebiasaan dan pembiasaan positif yang tinggi. Hanya saja, pada kategori tinggi tersebut tetap ada sekolah yang berada pada batas bawah dan batas atas kategori. Seperti dapat dilihat dalam Gambar 1, bahwa secara umum SDN Karang Yudha berada di batas bawah kategori tinggi, sedangkan SDN 2 Kedungdawa dan SDN Sadagori 1 berada pada batas atas kategori tinggi. Nilai tinggi yang didapat oleh kedua SD ini diperoleh dari nilai kebiasaan dan pembiasaan positif yang diterapkan oleh pihak sekolah. Hal ini tetap menunjukkan perbedaan nilai kultur dan pembiasaan positif yang diterapkan di sekolah.

Perilaku religius siswa didapat dari Lembar wawancara mengenai karakter religius yang terdiri atas 25 pernyataan yang terbagi menjadi dua kategori, yakni (1) hubungan dengan Allah Swt., dan (2) hubungan dengan sesama manusia. Tiap pertanyaan memiliki pilihan jawaban "ya" dan "tidak". Tiap jawaban "ya" akan diberi nilai 1 dan jawaban "tidak" akan diberi nilai 0 . Adapun skor/jumlah nilai karakter religius untuk tiap sekolah dapat dilihat pada Gambar 2.

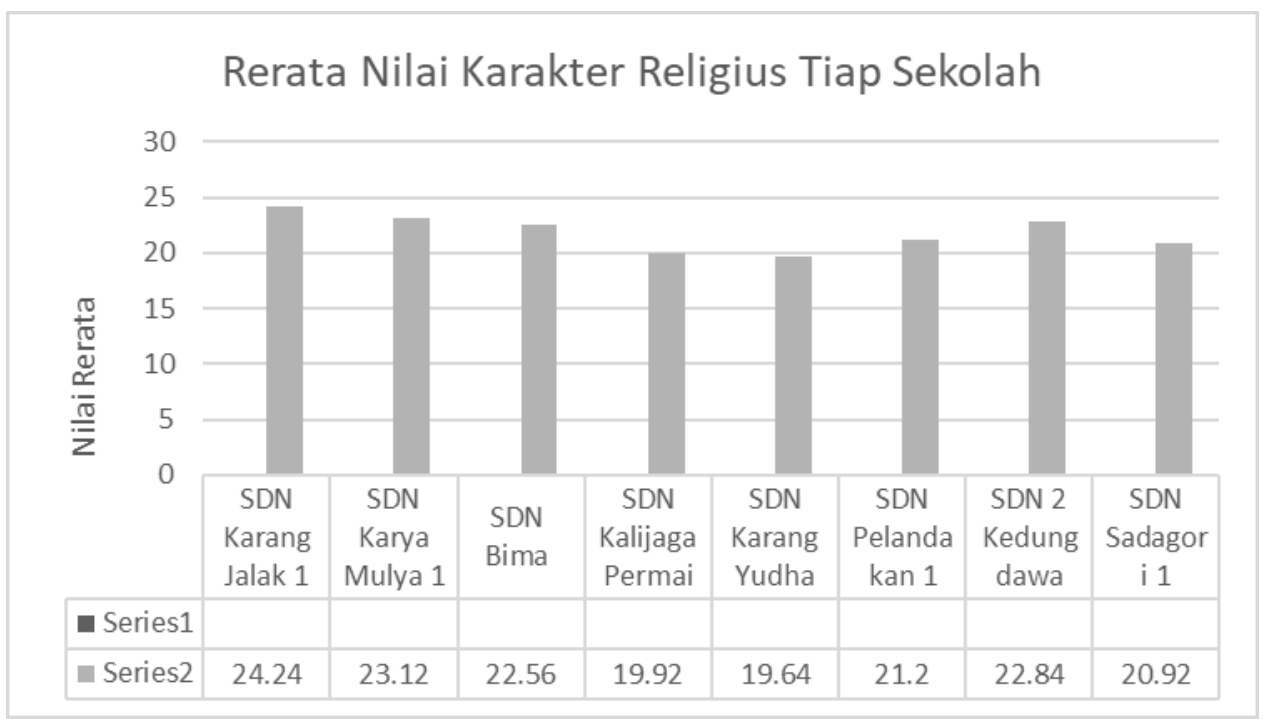

Gambar 2 Rerata Nilai Karakter Religius Tiap Sekolah

Berdasarkan gambar di atas, dapat dilihat bahwa SDN Karangjalak 1 mendapat nilai tertinggi diikuti SDN Karya Mulya 1 dan SDN 2 Kedungdawa. Nilai karakter religus tertinggi yang didapat oleh SDN
Karang Jalak 1 ini tak terlepas dari fakta bahwa SDN Karang Jalak 1 memiliki pembiasaan mengaji ayat suci Al-Quran dan berdoa sebelum memulai kegiatan pembelajaran serta diakhiri dengan doa sebelum pulang 
setiap harinya. Kebiasaan 3S yaitu senyum, sapa, dan salam dilakukan oleh guru maupun sesama teman serta seringnya sekolah memeringati hari-hari besar agama terutama Agama Islam dan tagline/slogan keagamaan berupa kaligrafi Asmaa-ul Husna pada setiap kelas.

Adapun karakter peduli lingkungan siswa diukur menggunakan lembar wawancara mengenai karakter peduli lingkungan yang terdiri atas 15 pernyataan yang dapat mengukur kepedulian siswa terhadap keadaan lingkungan sekitarnya terutama di sekolah. Tiap pertanyaan memiliki pilihan jawaban "ya" dan "tidak". Tiap jawaban "ya" akan diberi nilai 1 dan jawaban "tidak" akan diberi nilai 0 . Adapun skor/jumlah nilai karakter peduli lingkungan untuk tiap sekolah dapat dilihat pada Gambar 3.

\section{Rerata Nilai Karakter Peduli Lingkungan Tiap Sekolah}

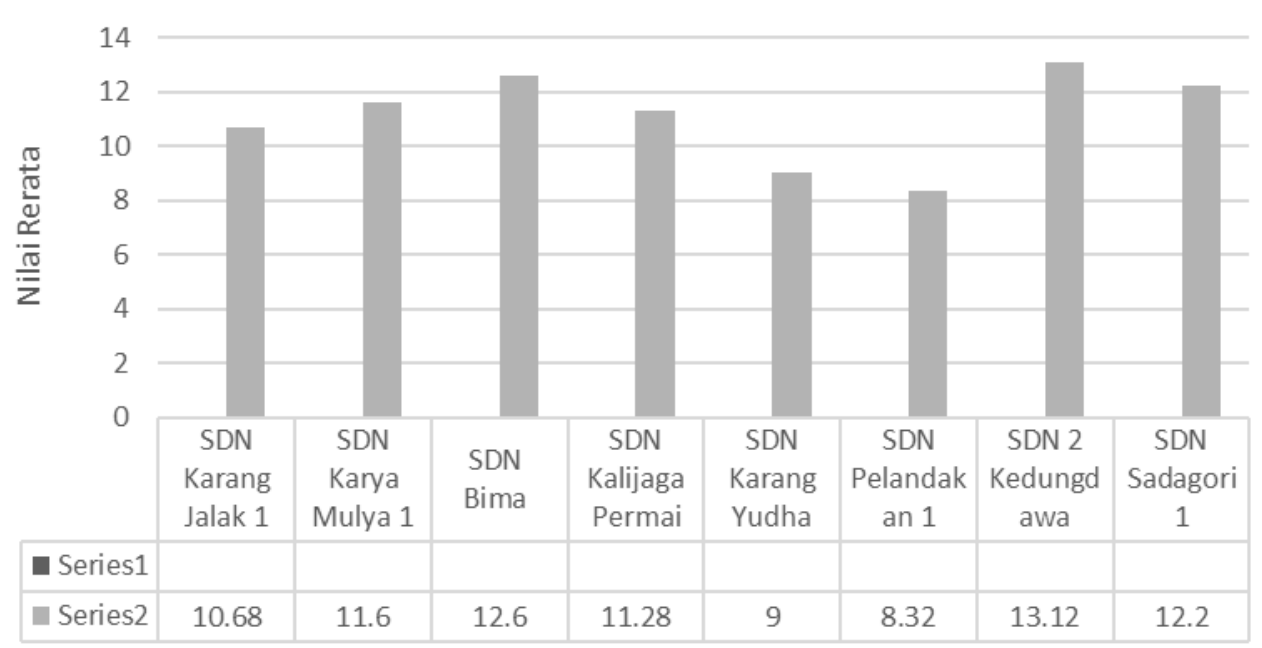

Gambar 3 Rerata Nilai Karakter Peduli Lingkungan Tiap Sekolah

Berdasarkan hasil wawancara terhadap sejumlah siswa mengenai kepedulian terhadap lingkungan, didapat bahwa siswa pada SDN 2 Kedungdawa memiliki nilai tertinggi pada karakter peduli lingkungan diikuti oleh SDN Bima dan SDN Sadagori 1. Nilai tertinggi pada karakter peduli lingkungan ini didapat oleh SDN 2 Kedungdawa berdasarkan fakta bahwa SDN 2 Kedungdawa memiliki tagline/slogan kepedulian terhadap lingkungan di setiap sudut ruang kelas dan sekolah yang senantiasa membiasakan siswa untuk memilah dalam membuang sampah berdasarkan kategori organik dan anorganik.

Hasil Uji Regresi untuk mencari besar pengaruh kultur dan pembiasaan positif di sekolah terhadap perilaku religius siswa dapat dilihat pada Tabel 1.

Tabel 1

Hasil Uji Pengaruh Kultur Sekolah Terhadap Karakter Religius

\begin{tabular}{lrrrr}
\hline Model & $\mathrm{R}$ & $\mathrm{R}$ Square & Adjusted R Square Std. Error of the Estimate \\
dimensiono & $1.561^{\mathrm{a}}$ & .314 & .200 & .891268
\end{tabular}

a. Predictors: (Constant), Nilai Kultur 
Berdasarkan Tabel 1, dapat dilihat bahwa nilai $R^{2}$ adalah 0,314 , hal ini berarti bahwa kultur dan pembiasaan positif di sekolah memengaruhi perilaku religius siswa sekolah dasar sebesar $31,4 \%$ sedangkan $68,6 \%$ sisanya dipengaruhi oleh faktor lain. Hasil uji signifikansi regresi dapat dilinat pada Tabel 2.

\section{Tabel 2}

Uji Signifikansi Regresi Pengaruh Kultur Sekolah Terhadap Karakter Religius

\begin{tabular}{|c|c|c|c|c|c|c|}
\hline \multirow[t]{2}{*}{ Mode } & & \multirow{2}{*}{$\begin{array}{l}\text { Sum of } \\
\text { Squares }\end{array}$} & \multicolumn{3}{|c|}{ Mean } & \multirow[b]{2}{*}{ Sig. } \\
\hline & & & df & Square & $\mathrm{F}$ & \\
\hline 1 & $\begin{array}{l}\text { Regressio } \\
\mathrm{n}\end{array}$ & 2.184 & 1 & 2.184 & 2.750 & $.148^{\circ}$ \\
\hline & Residual & 4.766 & 6 & .794 & & \\
\hline & Total & 6.950 & 7 & & & \\
\hline
\end{tabular}

Berdasarkan hasil uji signifikansi memengaruhi perilaku religius siswa regresi, didapat nilai Sig. sebesar sekolah dasar di Kota Cirebon.

0,148 . Hasil ini menunjukkan bahwa Adapun untuk uji pengaruh kultur dan kultur dan pembiasaan positif di pembiasaan positif di sekolah sekolah tidak secara signifikan terhadap karakter peduli lingkungan dapat dilihat pada Tabel 3 .

\section{Tabel 3}

Tabel Uji Pengaruh Terhadap Karakter Peduli Lingkungan

\begin{tabular}{|c|c|c|c|}
\hline Model & R Square & Adjusted R Square & Std. Error of the Estimate \\
\hline dimension0 $1.584^{\mathrm{a}}$ & .341 & 231 & \\
\hline
\end{tabular}

Berdasarkan Tabel 3, dapat dilihat sekolah dasar sebesar 34,1\% bahwa nilai $R^{2}$ adalah 0,341 , hal ini sedangkan $65,9 \%$ sisanya berarti bahwa kultur dan pembiasaan dipengaruhi oleh faktor lain. Hasil uji positif di sekolah memengaruhi signifikansi regresi dapat dilhat pada perilaku peduli lingkungan siswa Tabel 4.

\section{Tabel 4}

Uji Signifikansi Regresi Pengaruh Kultur Sekolah Terhadap Karakter Religius

\begin{tabular}{|c|c|c|c|c|c|c|}
\hline \multicolumn{2}{|c|}{ Model } & \multirow{2}{*}{$\begin{array}{l}\text { Sum of } \\
\text { Squares }\end{array}$} & \multicolumn{3}{|c|}{ Mean } & \multirow[b]{2}{*}{ Sig. } \\
\hline & & & df & Square & $\mathrm{F}$ & \\
\hline 1 & $\begin{array}{l}\text { Regressio } \\
\mathrm{n}\end{array}$ & 2.444 & 1 & 2.444 & 3.104 & $.129^{a}$ \\
\hline & Residual & 4.724 & 6 & .787 & & \\
\hline & Total & 7.168 & 7 & & & \\
\hline
\end{tabular}

Berdasarkan hasil uji signifikansi kultur dan pembiasaan positif di regresi, didapat nilai Sig. sebesar sekolah tidak secara signifikan 0,129 . Hasil ini menunjukkan bahwa memengaruhi karakter peduli 
lingkungan siswa sekolah dasar di KotaCirebon.

\section{SIMPULAN}

Berdasarkan hasil penelitian dan pengolahan data yang telah dilakukan, peneliti dapat menyimpulkan beberapa hal diantaranya bahwa seluruh siswa yang dijadikan sampel penelitian memiliki karakter religius yang baik/tinggi, sedangkan untuk karakter peduli lingkungan, hanya dua dari delapan sampel sekolah yang memiliki nilai yang termasuk dalam kategori sedang dan enam sekolah lainnya memiliki nilai baik/tinggi. Berdasarkan hasil uji regresi dapat disimpulkan bahwa kultur dan pembiasaan positif di sekolah tidak secara signifikan memengaruhi perilaku religius dan kepedulian siswa sekolah dasar terhadap lingkungannya. Meskipun tidak signifikan, bukan berarti kultur dan pembiasaan positif di sekolah tidak memiliki pengaruh terhadap perilaku religius dan kepedulian lingkungan siswa sekolah dasar. Pengaruh tetap ada, hanya saja nilai pengaruhnya tidak terlalu besar. Untuk itu, kultur dan pembiasaan positif di sekolah tetap harus dilaksanakan, dievaluasi dan ditingkatkan oleh pihak sekolah agar didapatkan siswa yang kuat dan sempurna secara kognitif, psikomotor, dan afektif (sikap dan karakter).

\section{DAFTAR PUSTAKA}

Al-Anwari, A., M., (2014). "Strategi Pembentukan Karakter Peduli Lingkungan Di Sekolah Adiwiyata Mandiri," Ta'Dib, vol. 19, no. 2, pp. 227-252.

Desfandi, M., (2016). "Mewujudkan Masyarakat Berkarakter Peduli Lingkungan Melalui Program Adiwiyata," SOSIO Didakt. Soc. Sci. Educ. J., vol. 2, no. 1, pp. 31-37.

Gunawan, H., (2017). Pendidikan Karakter Konsep dan Implementasi. Bandung. Alfabeta.

Jumadi, (2005). "PERANAN KULTUR SEKOLAH TERHADAP KINERJA GURU, MOTIVASI BERPRESTASI DAN PRESTASI BELAJAR IPA SISWA." pp. 217-228.

Keawkhong, C., (2014). "Issue 5 Article 52014 This Journal Article is posted at Research
Online. Recommended Citation Hongboontri," Aust. J. Teach. Educ., vol. 39, no. 5, p. 39.

Lickona, T., (2008). Pendidikan Karakter Panduan Lengkap Mendidik Siswa Menjadi Pintar dan Baik. Bandung. Nusa Media.

MacNeil, A., J., Prater, D., L., and Busch, S., (2009). "The effects of school culture and climate on student achievement," Int. J. Leadersh. Educ., vol. 12, no. 1, pp. 73-84.

Mujtahidin, (2017). Civic Education Di Sekolah: Penguatan Pendidikan Karakter Melalui Pembelajaran PKn yang inovatf dan Efektif. Surabaya: Pustaka Radja.

Setyati, S., (2014). "Pengaruh Kepemimpinan Kepala Sekolah , Motivasi," J. Pendidik. Teknol. Dan Kejuru., vol. 2, pp. 200207. 
Sultoni, A., (2017). "Implementasi Kurikulum $2013 \quad$ Dalam Mengembangkan Sikap Religius Siswa Melalui Bidang Studi Biologi Di Madrasah Aliyah," J. Pendidik. Agama Islam (Journal Islam. Educ. Stud., vol. 4, no. 1, p. 68.

Wilis, S., S., (2012). Psikologi Pendidikan. Bandung. Alfabeta. Yusuf, S., (2007). Buku Materi Pokok Pedagogik Pendidikan Dasar. Bandung: Sekolah Pascasarjana Universitas Pendidikan Indonesia. 